\title{
Is inadequate anatomical knowledge on the part of physicians hazardous for successful clinical practice?
}

\author{
Rajani Singh $^{1}$ (1) $\cdot$ Nisha Yadav $^{1} \cdot$ Manisha Pandey $^{1} \cdot$ David Gareth Jones $^{2}$
}

Received: 4 August 2021 / Accepted: 20 December 2021 / Published online: 7 January 2022

(c) The Author(s), under exclusive licence to Springer-Verlag France SAS, part of Springer Nature 2021

\begin{abstract}
Purpose The physicians say that the least anatomy is required for clinical practice. But the disease causes anatomical distortions or variations in structures impairing functions of organs and systems. So, the diagnosis and analysis of treatment of disease depend on interwoven inter-relationship among Anatomy, Physiology, Pathology, Radiology and clinical sciences. Consequently, the upcoming doctors are to be cultivated sufficient anatomy. Therefore, the objective of this study is to analyze viewpoints of medical students, faculties and practitioners regarding degree of need of Anatomy in clinical practice.

Methods A feedback survey has been carried out among students and faculties to seek their views on the need of Anatomy in clinical practice using two hypotheses. Hypothesis 1 defines the degree of need of Anatomy ('most essential', 'essential' and 'least essential') in clinical practice based on answers of questionnaire by medical students and faculties, whereas hypothesis 2 assigns weights depending on knowledge and experience of the feedback providers. The means/weighted means of views have been statistically analyzed. Additionally, the literature survey was carried out on the demand, necessity, importance, usefulness and applicability of Anatomy in clinical practice.

Results Our statistical analysis revealed that Anatomy is 'most essential' for clinical practice. In literature survey too, the inadequate knowledge of anatomy among medical students leads to poor comprehension of clinical practice. So, anatomy is most essential for clinical practice.
\end{abstract}

Conclusion Sound knowledge of Human Anatomy is most essential during medical practice for Physicians.

Keywords Anatomy $\cdot$ Radiology $\cdot$ Medical practice $\cdot$ Physician

\section{Introduction}

Human Anatomy teaching/learning cultivates the language of medicine as many of the terms, used in medicine, originate from anatomic parts and their functions/orientations, such as anterior-posterior, palmar-plantar, proximal-distal, external-internal, abduction-adduction, elevation-depression, and protraction-retraction. Beahrs [3] has commented "How then can a student of medicine not know Anatomy and claim to understand the language of medicine?" Medical education/science has evolved from Anatomy, for instance, pathology is morbid Anatomy; embryology is science of

Rajani Singh

nani_sahayal@rediffmail.com

1 Department of Anatomy, Uttar Pradesh University of Medical Sciences, Saifai, Etawah, UP, India

2 Department of Anatomy, Otago University, Otago, New Zealand developmental processes and genetic anomalies; cytology and histology deals with study of microanatomy; physiology describes functions of structures, organs and systems [3]. In the clinical domain, Radiology is the analysis of images of anatomical structures; Microbiology is anatomy of micro-organisms causing diseases while surgery is the science and art of manipulation, removal and replacement of morbid structures (Fig. 1) and medicine in turn encompasses manipulation, restoration, activation, or dissolution of extra growth in bones, hard masses, stones, injury, extra-development of bodies and variant attachment of tendon/ligaments/ fibers pertaining to musculoskeletal anatomy [22] in organs/ systems and degeneration of macro/microstructures due to interaction of two structures and suppression of uncomfortable exigent signs and symptoms (Fig. 1). Thus, none of these subjects can be comprehended fully well, if the learners ignore elements of gross and microanatomy. In addition to this, the knowledge of Anatomy is directly needed in the diagnosis and treatment of disease through clinical practice. 


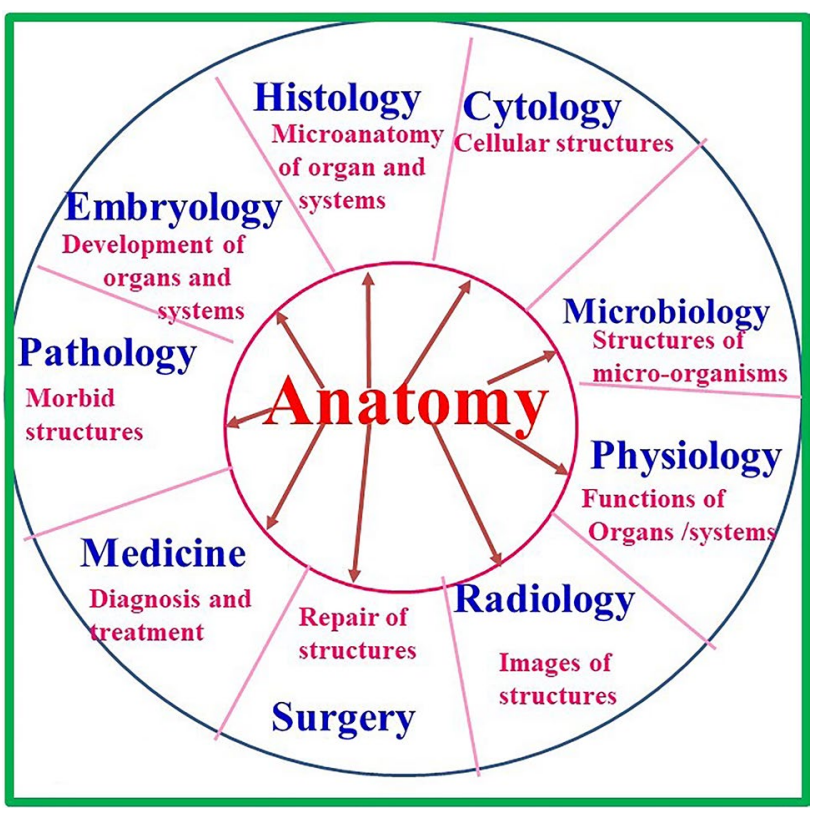

Fig. 1 Shows how various subjects of Medical Education evolved from Anatomy

In daily medical practice, "anatomy is important for physical examination, symptom interpretation and interpretation of radiological images. Knowledge of anatomy is essential for understanding neurological or musculoskeletal disorders [23]."

Even the students realized the relevance of Anatomy in clinical practice as they emphasized in a feedback study of Bergman et al. [4], "You need it for diagnosis; you need it for physical examination, for hand-over to colleagues, for record keeping, for writing letters, in fact for understanding how certain processes work, why patients are ill and what should be done about it."

However, full realization of the relevance of Anatomy and its intrinsic value in medicine comes only after extensive clinical experience. Senior students commented: "in the clerkships, I suddenly, they thought, hey! At this point it would have been really useful if I had studied a bit more Anatomy." Moreover, the students during their neurology clerkship mentioned: "I am doing neurology now and there you discover that every diagnosis, everything comes down to Anatomy in the end and how things run and work, that is really awfully important" [4].

In the study of Priyadharshini et al. [26], "the 4th semester students, interns, and clinicians perceived Anatomy to be highly relevant to their day-to-day practice. Clinicians in our survey perceived the role of anatomy in the clinic as important, particularly during the physical examination, interpreting radiological images, and communication with colleagues. Physicians become less aware of the foundational knowledge required for their clinical reasoning skills
[26]." In addition to this, the relevance of Anatomy in clinical practice has been highlighted in detail in a very good editorial, recently, by Duparc et al. [12]

Apart from this, there are many grey areas in Anatomy which are directly related to clinical practice together with the clinical grey areas completely dependent on Anatomy are to be discovered by standalone and/or collaborative research to strengthen the medicinal practice. The everexpanding array of newer diagnostic methodologies, including the innovations in the way the body can be visualized (e.g., computed tomography, magnetic resonance imaging scans), require a specific level of anatomical knowledge [26]. In an earlier study, Barlow [2] commented that endoscopic and laparoscopic procedures demand a clinically oriented Anatomy.

Many authors have drawn attention to the way in which anatomy has been ignored or at the least neglected by medical school owners and officials, but also by clinicians and students [3, 5, 9, 13, 15, 16, 19, 24, 27, 28, 31, 32, 34, 36] leading to acquisition/delivery of inadequate Anatomy to pursue successful clinical practice. The result has been a fall in the standard of medical education, with in some cases, an increase in litigations [13] due to anatomical ignorance in diagnosis and treatment by physicians and surgeons $[4,6$, 14, 17, 20, 34].

Authors have repeatedly put this down to the drastic reductions in anatomical teaching schedules [11, 21, 30], pruning of anatomical curricula [11, 29], closure Anatomy departments $[6,10,29]$ including dissection halls and nonrecruitment of medically qualified faculties $[7,11,18,25$, $29,35]$. The context, within which these developments have taken place, has been that only limited amounts of Anatomy are adequate for clinical practice. This concept has to be reviewed. Inevitably, these expectations have influenced medical students who have been brought up to be content with what we would regard as an inadequate core content of Anatomy. In our estimation this is a pseudo-concept, in which small non-cohesive segments of Anatomy have been regarded as an acceptable fundamental base for the many diverse areas of clinical practice.

All this put together loudly speak that though it is most important constituent of clinical practice yet there is silent murmur among physicians practicing medicinal treatment that least anatomy is required in their practice. Therefore, this study has been designed to evaluate the intimate interwoven inter-relationship between Anatomy, a range of diseases, functions and activities of organs and systems of human body and the diagnosis and analysis of available medicinal treatments for safe clinical practice. Consequently, the evaluation of these parameters on the basis of feedback sought from students, faculties/medical practitioners through a questionnaire based on the demand, necessity, importance, usefulness and applicability of human Anatomy 
in clinical practice and review of literature including our own analysis. Thus, the objective of study is to explore the validity of concept, 'Is inadequate anatomical knowledge on the part of physicians hazardous for successful clinical practice?' in clinical practice evaluating feedback data from students and faculty.

\section{Materials and methods}

To meet the objective of study, an experiment has been planned to seek opinion of 386 undergraduate students (UGs) and 6 interns, 105 postgraduate medical students (PGs), 10 Post-PG Super-specialty students (P PGs), 31 Non-Clinical Faculties (NCFs) and 60 Clinical Faculties (CFs) in UP University of Medical Sciences Saifai Etawah UP India, regarding the demand, necessity, importance, usefulness and applicability of human Anatomy in clinical practice. So, during Aug.-Nov. 2020, a questionnaire consisting of 15 questions was designed to cover the application and need of Anatomy in clinical practice as analyzed by authors and illustrated by [3, 4, 26, 33] Bearhs, Standring, Bergman et al., Priyadarshini et al., etc., consisting of the diagnosis and analysis of treatment of disease in clinical practice by physicians through medicinal treatment. Such as, "Do the variations in anatomical macro/microstructures require to analyze the functions, activities and configuration of organs and systems?" A) Yes, B) No. The questions have been so designed that the populations were to answer these questions in yes $(Y)$ or no $(N)$. Ys represent need and Ns no need. Thus, varying numbers of Ys represent viewpoints of various populations regarding the degree of need of Anatomy in clinical practice. For example, the responders have been asked in one of the questions, "Is precise knowledge of surface Anatomy required for observation, palpation, percussion and auscultation at accurate location?" A) Yes, B) No. The degrees have been defined in hypothesis 1 on a three-point scale.

Hypothesis 1 The degree of need of Anatomy in clinical practice has been conceptualized as the knowledge of Anatomy to be "Most essential", if the means of viewpoints of group of populations in terms of Ys fall in the range of 10-15 (67-100\%), "Essential”, in the range, 6-9 (40-60\%) and "Least essential" in the range 1-5 (6-33\%) (Table 1) on a three-point scale. A similar pattern has been defined for the diagnosis and analysis of treatment (Table 1). Here, the generalized means of viewpoints of all the groups of the subjects have been computed irrespective of knowledge and experience of both Anatomy and clinical practice whereas the sample space possess diversified populations starting from fresh medical entrants to expert teaching faculties. So, the pattern of answers is highly divergent due to variation in knowledge and experience of populations in Anatomy and Clinical practice both.

Therefore, weighted means of viewpoints were also calculated for more focused opinion of population considering their knowledge and experience in Anatomy and clinical practice. If the means of viewpoints are qualified by knowledge and experience of Anatomy, its application and analysis of clinical care together with knowledge and experience in clinical care, the mean viewpoints of the total population is modified/refined by applying weightage/importance of knowledge and experience. These weightages have been defined in hypothesis 2 .

Hypothesis 2 The Fresh entrants, the students of first semester of MBBS Ist year, have very limited exposure to both Anatomy and clinical practice therefore, questions pertaining to distorted macro/micro-anatomical structures, due to external/internal pathogens, toxins, drugs, environmental hazards, external traumas/internal lesions due to iatrogenic causes and misuse of organs/limbs and congenital anomalies or otherwise, generating diseases through impairment of functions/activities will be almost incomprehensible to them not to speak of knowing the interwoven interrelationship among these parameters to analyze the diagnosis and treatment. So, their viewpoints will certainly influence the mean viewpoints of the students of IInd, IIIrd, IVth and Final year as all of them constitute the UG group. The other populations too have variation in their knowledge and experience in Anatomy and clinical analysis but not to that extent so the following weightage has been conceptualized.

Thus, hypothesis 2 has been propounded which states that the weightage/importance has been given $100 \%$ to viewpoints of clinical faculties (CFs) and Post Post-graduate
Table 1 The concepts on degree of need of Anatomy in clinical care, diagnosis and treatment

\begin{tabular}{|c|c|c|c|c|c|c|}
\hline \multicolumn{2}{|c|}{ Clinical care } & \multicolumn{2}{|c|}{ Diagnosis } & \multicolumn{2}{|c|}{ Treatment } & \multirow[t]{2}{*}{ Degree of need } \\
\hline Ys & $\%$ & Ys & $\%$ & Ys & $\%$ & \\
\hline $10-15$ & $67-100$ & $7-11$ & $63-100$ & $3-5$ & $60-100$ & Most essential \\
\hline $6-9$ & $40-60$ & $4-6$ & $36-55$ & 2 & 40 & Essential \\
\hline $1-5$ & $6-33$ & $1-3$ & $9-27$ & 1 & 10 & Least essential \\
\hline
\end{tabular}

$Y s$ represent viewpoints of need of Anatomy by various populations, \% is corresponding percentages of Ys 
superspecialists (P PGs) because these group of populations face constraints of anatomical knowledge in their day today clinical practice providing real feedback, $65 \%$ to non-clinical medical faculties (NCFs) and post-graduating students (PGs) because the NCFs have no clinical exposure together with forgotten Anatomy and PGs include PGs from clinical side and non-clinical students so have variant knowledge and experience in Anatomy and clinical practice both.60\% to graduating students, UGs consisting of the students from Ist year to final-year and Interns (Table 2).

As illustrated above, the groups have diversified knowledge and experience so the mean viewpoints are divergent. So, to achieve more focused viewpoints, the weighted means of total population have been calculated by applying proper weightages as defined in Hypothesis 2. This mean again gives overall weighted mean viewpoints of total population. To further sharpen and making more comprehensible inference, the total \% of Ys emphasizing Anatomy to be most essential, essential and least essential have been computed. In addition to this, the \% of responders in various groups, who expressed that Anatomy is most essential, essential and least essential, has also been calculated.

This analysis, together with the literature pertaining to the demand, necessity, importance, usefulness and applicability of human Anatomy in clinical practice, was reviewed. The dependence of diagnosis and treatments on human Anatomy was analyzed. The hazards of inadequate knowledge of Anatomy in clinical practice in general and medicinal treatment in particular were also explored and discussed. The effects of unknown variations in interwoven relations among shapes, sizes, locations and orientations of structures, organs and limbs, their configuration, pathways, functions, and antigens to be detected through physical examination, radiological images and their interpretation including the signatures of diseases on these morphological elements have been explored and assessed for successful clinical practice.

The permission to seek views of UGs, PGs, PPGs and faculties of our institute was taken from Dean (Faculty of Medicine). The participants were verbally informed that their views were used for research purpose. Ethical clearance for the study was obtained from Institutional Ethical Committee vide no. 142/2020-21.

Table 2 The concept of weightage depending on knowledge and experience of populations

\begin{tabular}{lll}
\hline Subject & \multicolumn{2}{l}{$\begin{array}{l}\text { Weightage in } \% \\
\text { and fraction }\end{array}$} \\
\hline UGs + Interns & 60 & 0.6 \\
PG Students + Non-clinical Faculties & 65 & 0.65 \\
Post PG Students + Clinical faculties & 100 & 1.0 \\
\hline
\end{tabular}

UGs undergraduate medical students, $P G s$ postgraduate medical students

\section{Results}

The computed generalized and weighted means of viewpoints of all the groups individually are shown in the tables pertaining separately, to total clinical practice (Table 3), diagnosis (Table 4) and treatment (Table 5). It can be clearly seen from the generalized means that particularly, the UGs studying medicine in various years and semesters have limited exposure to both Anatomy and clinical practice so their viewpoints, on questions like, "while understanding malfunctions of organs/systems, is the knowledge of organization and shape, size, location and orientation of structures not required?" A) Yes, B) No., are not only highly divergent but also having skew values. The range of Ys (viewpoint to express degree of need of Anatomy in clinical Analysis) from UGs spreads in the range from 5 to 15 having maximum divergence in the questions pertaining to overall

Table 3 Generalized mean viewpoints on need of Anatomy in clinical practice

\begin{tabular}{lll}
\hline Populations & Mean \pm S.D & Degree of need \\
\hline UGs & $11.1 \pm 2.2$ & ME \\
Interns & $12 \pm 0.6$ & ME \\
PGs & $11.6 \pm 1.74$ & ME \\
NCFs & $12.55 \pm 2.11$ & ME \\
P PGs & $13.1 \pm 1.5$ & ME \\
CFs & $13.2 \pm 1.71$ & ME \\
Weighted mean of & 12.2 & ME \\
UGs + Interns $+\boldsymbol{P G s}+\boldsymbol{N C F}+\boldsymbol{P}$ & & \\
PGs + CFs & & \\
\hline
\end{tabular}

$U G s$ undergraduate medical students, $P G s$ post-graduate medical students, $P$ PGs post postgraduate medical students, NCFs non-clinical faculties, $C F s$ clinical faculties, S.D. standard deviation, $M E$ most essential degree of need of Anatomy

Table 4 Mean viewpoints on need of Anatomy in diagnosis

\begin{tabular}{lll}
\hline Populations & Mean \pm S.D & Degree of need \\
\hline UGs & $8.4 \pm 1.5$ & ME \\
Interns & $9.0 \pm 0.6$ & ME \\
PGs & $9.5 \pm 1$ & ME \\
NCFs & $9.7 \pm 1.2$ & ME \\
P PGs & $9.7 \pm 1.3$ & ME \\
CFs & $10.2 \pm 0.9$ & ME \\
Weighted mean of & 9.5 & ME \\
$\quad$ UGs + Interns $+\boldsymbol{P G s}+\boldsymbol{N C F} \boldsymbol{+}+\boldsymbol{P}$ & & \\
PGs +CFs & & \\
\hline
\end{tabular}

UGs undergraduate medical students, $P G s$ post-graduate medical students, $P$ PGs post postgraduate medical students, NCFs non-clinical faculties, $C F s$ clinical faculties, S.D. standard deviation, $M E$ most essential degree of need of Anatomy 
Table 5 Mean viewpoints on need of Anatomy in treatment analysis

\begin{tabular}{lll}
\hline Populations & Mean \pm S.D & Degree of need \\
\hline UGs & $3.8 \pm 0.1$ & ME \\
Interns & $3.8 \pm 0.4$ & ME \\
PGs & $4 \pm 0.9$ & ME \\
NCFs & $4.3 \pm 0.8$ & ME \\
P PGs & $4.2 \pm 0.9$ & ME \\
CFs & $4.4 \pm 0.9$ & ME \\
Weighted mean of & 4.1 & ME \\
$\quad$ UGs + Interns $+\boldsymbol{P G s}+\boldsymbol{N C F} \boldsymbol{P}+\boldsymbol{P}$ & & \\
\hline
\end{tabular}

$U G s$ undergraduate medical students, $P G s$ post-graduate medical students, $P P G s$ post postgraduate medical students, NCFs non-clinical faculties, $C F s$ clinical faculties, S.D. standard deviation, $M E$ most essential degree of need of Anatomy

clinical practice whereas, these ranges of Ys expressed by PGs, Interns, P PGs, NCFs and CFs are 9-15, 11-13, $11-15,10-15$ and $9-15$, respectively having less diverged data than UGs. Similar is the case for questions in diagnosis and treatment. In addition to this, the data of mean statistics have divergence as large as from $11.1 \pm 2.2$ to
$13.2 \pm 1.71$ in clinical practice, from $8.4 \pm 1.5$ to $10.2 \pm 0.9$ in diagnosis and from $3.8 \pm 0.1$ to $4.4 \pm 0.9$ for analysis of treatment (Tables 3, 4, 5). Here the lowest degree of need of Anatomy for most essential is from UGs and highest degree of need of Anatomy among most essential is from CFs with divergence as large as 2.2 in standard deviation for UGs. This loudly speaks that maximum divergence of Ys is from UGs and minimum deviation in CFs. These results support our Hypothesis 2. However, 'most essential' degree of need has been expressed by $77.7 \%$ UGs, $91 \%$ by PGs, $100 \%$ by Interns, P PGs, NCFs and $98 \%$ by CFs for clinical practice, similarly for diagnosis and treatment (Tables 6,7,8). Out of total Ys (contributing to the 3 degrees of need of Anatomy), majority ranging from 61.4 to $87 \%, 74$ to $93 \%$ and 72.5 to $86 \%$ contribute to 'most essential', 0 to $12.4 \%, 0$ to $2 \%$ and 0 to $2.2 \%$ to essential and almost no Ys have been given by responders for 'least essential' (Tables 6, 7, 8).

The weighted means of total population improve the degree of need of Anatomy in clinical practice together with diagnosis and treatment from 11.5 to $12.2,8.9$ to 9.5 and 3.9 to 4.1 remaining in the range of 'most essential' Ys. The individual means of Ys from all the groups separately can be seen in detail from the tables which again fall in the
Table 6 Showing \% of responders, \% of Ys supporting need of Anatomy in clinical practice in each of the three degrees "most essential", "essential" and "least essential" and $\%$ of Ys for each group of responders

\begin{tabular}{|c|c|c|c|c|c|c|c|}
\hline \multirow[t]{2}{*}{ Groups } & \multicolumn{3}{|l|}{$R \%$} & \multicolumn{3}{|l|}{ Ys \% } & \multirow[t]{2}{*}{$T \%$ of $\mathrm{Ys}$} \\
\hline & For ME & For E & For LE & For ME & For E & For LE & \\
\hline UGs & 77.7 & 22 & 0.3 & 61.4 & 12.4 & 0.001 & 74 \\
\hline Interns & 100 & 0 & 0 & 80 & 0 & 0 & 80 \\
\hline PGs & 91 & 8 & 0 & 72 & 5 & 0 & 77 \\
\hline PPGs & 100 & 0 & 0 & 87 & 0 & 0 & 87 \\
\hline NCFs & 100 & 0 & 0 & 84 & 0 & 0 & 84 \\
\hline $\mathrm{CFs}$ & 98 & 2 & 0 & 87 & 1 & 0 & 88 \\
\hline Total P & 83.6 & 16.2 & 0.2 & & & & \\
\hline
\end{tabular}

$R$ responders, $T$ total, $Y s$ are the viewpoints supporting Anatomy is most essential, $M E$ most essential, $E$ essential, $L E$ least essential, $U G s$ undergraduate medical students, $P G s$ post-graduate medical students, $P P G s$ post $\mathrm{PGs}, N C F s$ non-clinical faculties, $C F$ s clinical faculties, $P$ population, $\%$ percentage

Table 7 Showing \% of responders, \% of Ys supporting need of Anatomy in diagnosis in each of the three degrees "most essential", "essential" and "least essential" and \% of Ys for each group of responders

\begin{tabular}{|c|c|c|c|c|c|c|c|}
\hline \multirow[t]{2}{*}{ Groups } & \multicolumn{3}{|l|}{$R \%$} & \multicolumn{3}{|l|}{ Ys \% } & \multirow[t]{2}{*}{$T \%$ of $\mathrm{Ys}$} \\
\hline & For ME & For E & For LE & For ME & For E & For LE & \\
\hline UGs & 95 & 5 & 0 & 74 & 2 & 0 & 76 \\
\hline Interns & 100 & 0 & 0 & 82 & 0 & 0 & 82 \\
\hline PGs & 97 & 3 & 0 & 84.5 & 1.5 & 0 & 86 \\
\hline PPGs & 100 & 0 & 0 & 88 & 0 & 0 & 88 \\
\hline NCFs & 100 & 0 & 0 & 88 & 0 & 0 & 88 \\
\hline CFs & 100 & 0 & 0 & 93 & 0 & 0 & 93 \\
\hline Total P & 97 & 3 & 0 & & & & \\
\hline
\end{tabular}

$R$ responders, $T$ total, $Y S$ are the viewpoints supporting anatomy is most essential, $M E$ most essential, $E$ essential, $L E$ least essential, UGs undergraduate medical students, $P G s$ post-graduate medical students, $P P G s$ post PGs, NCFs non-clinical faculties, $C F s$ clinical faculties, $P$ population, $\%$ percentage 
Table 8 Showing $\%$ of responders, \% of Ys supporting need of Anatomy in analysis of treatment in each of the three degrees "most essential", "essential" and "least essential" and $\%$ of Ys for each group of responders

\begin{tabular}{|c|c|c|c|c|c|c|c|}
\hline \multirow[t]{2}{*}{ Groups } & \multicolumn{3}{|l|}{$R \%$} & \multicolumn{3}{|l|}{ Ys $\%$} & \multirow[t]{2}{*}{$\mathrm{T} \%$ of $\mathrm{Ys}$} \\
\hline & For ME & For $\mathrm{E}$ & For LE & For ME & For E & For LE & \\
\hline UGs & 92.2 & 5.7 & 2.1 & 72.5 & 2.2 & 0.4 & 75.2 \\
\hline Interns & 100 & 0 & 0 & 76.7 & 0 & 0 & 76.7 \\
\hline PGs & 96 & 4 & 0 & 78.6 & 1.6 & 0 & 80.2 \\
\hline PPGs & 100 & 0 & 0 & 84 & 0 & 0 & 84 \\
\hline NCFs & 100 & 0 & 0 & 86 & 0 & 0 & 86 \\
\hline CFs & 96.7 & 3.3 & 0 & 86 & 1.3 & 0 & 87.3 \\
\hline Total P & 94 & 4.7 & 1.3 & & & & \\
\hline
\end{tabular}

$R$ responders, $T$ total, $Y s$ are the viewpoints supporting is most essential, $M E$ most essential, $E$ essential, $L E$ least essential, $U G s$ undergraduate medical students, $P G s$ post-graduate medical students, $P P G s$ post PGs, $N C F s$ non-clinical faculties, $C F s$ clinical faculties, $P$ population, \% percentage range of Ys for 'most essential'. 83.6 84\% of the responders from total population express the degree of Anatomy to be 'most essential', 16.2 16\% 'essential' and negligible $0.2 \%$ least essential in clinical practice; $97 \%$ of responders from total population express 'most essential', $3 \%$ 'essential' and none expresses 'least essential' in diagnosis whereas $94 \%$ of responders from total population express 'most essential', $4.7 \%$ 'essential' and 1.3\% express 'least essential' in treatment.

These are extremely beautiful results strongly supporting the degree of need of anatomical knowledge to be "most essential' in clinical practice. However, the presence of skew values was found in the feedback from chiefly UGs and mildly from PGs due to variant knowledge and experience of the sciences. These deteriorated the statistical means and $\%$ analysis to some extent. However, this was tried to be annulled by computing weighted mean.

\section{Discussion}

There are two basic pillars of this study. First is the statistical analysis of feedback survey regarding opinions of population groups, such as UGs, Interns, PGs, P PGs, NCFs and $C F s$ and total population. Second, the review and analysis of research literature regarding the degree of need of anatomical knowledge for successful clinical practice have also proved foundational.

\section{Statistical analysis of opinion feedback survey}

The students' opinion is important because they pursue medical education getting ready to enter into the medical profession. Whatever difficulties, they were facing in comprehending medical education and practically in clinical practice, will be revealed. This will add immense importance to study but with the constraint that they neither have enough experience in clinical analysis nor remember the clinically important anatomical variations. Though these students have been divided into four groups, namely UGs, PGs, Interns and P PGS, yet these groups too have diversified knowledge and experience. So it is pertinent to mention here that the first-year students of MBBS are exposed to clinical practice and anatomy in a very limited manner. However, IInd, IIrd, IVth and final-year students are conversant with pre-clinical Anatomy and clinical practice to some extent, so the mean viewpoints of UGs might have been distorted. PGs exercise the residual Anatomy after forgetting part of it together with they being from basic, para-clinical and clinical sciences. So, their viewpoints are also divergent. However, clinical PGs have acquired enough clinical experience to reveal the need of Anatomy. The basic sciences faculties consist of a spectrum of backgrounds, some are not medically qualified so devoid of clinical exposure and some might have forgotten Anatomy during their post-graduation and teaching career in different disciplines. This segment of population contributed to distorted mean viewpoints. The Post PGs and clinical faculties are mature and experienced clinicians with residual Anatomy studied, during preclinical phase and during self-studied clinical Anatomy during clinical practice, have clear concept regarding degree of need of anatomy. Therefore, their feedback has been regarded as most valuable. Since the number of UGs/PGs dominates the numbers of other groups so even after applying the weightage, the weighted mean of viewpoints is only slightly corrected.

To accomplice the objective, three-tier analyses have been carried out on the degree of need of Anatomy in clinical practice consisting of diagnosis and treatment. The means viewpoints of UGs in clinical practice, diagnosis, and analysis of treatment, respectively, $(11.1 \pm 2.2,8.4 \pm 1.5$, $3.8 \pm 0.1)$, Interns $(12 \pm 0.6,9.0 \pm 0.6,3.8 \pm 0.4)$, PGs (11.6 $\pm 1.74,9.5 \pm 1,4 \pm 0.9)$, P PGs (13.1 $\pm 1.5,9.7 \pm 1.3$, $4.2 \pm 0.9)$, NCFs $(12.55 \pm 2.11,9.7 \pm 1.2,4.3 \pm 0.8)$ and $)$ CFs $(13.2 \pm 1.71,10.2 \pm 0.9,4.4 \pm 0.9)$ which though fall well within the range of 'most essential' (10-15, 7-11, 3-5). This clearly states that the degree of need of Anatomy is 
'most essential' for all the groups as defined in Hypothesis 1. The application of weighted mean concept further enhances the degree of need of anatomical knowledge within the range of 'most essential' from 11.5, 8.9, 3.9 to 12.2, 9.5, 4.1 in clinical practice, diagnosis, and analysis of treatment, respectively.

Further percentage analysis of responders, group-wise and total population firmly establish that the degree of need of anatomical knowledge is 'most essential' by majority of individual groups, such as UGs $(77,95,92.2) \%$, Interns $(100,100,100) \%$, PGs $(91,97,96) \%$, P PGs $(100,100$, $100) \%, N C F s(100,100,100) \%$ and CFs $(98,100,96) \%$ and total population $(83.6,97,94) \%$ in clinical practice, diagnosis, and analysis of treatment.

In a survey carried out by Ahmed et al. revealed that all participants consisting of medical students, trainees and specialists agreed that knowledge of anatomy is important for medical practice and is perceived to be important for safe clinical practice [1].

Our study confirms that Anatomy is most essential for clinical practice and is also supported by previous studies $[1,23]$.

\section{Analysis of literature survey}

As the three-tier statistical analysis has been carried out from feedback survey on following heads, (1) Diagnosis, (2) Analysis treatment and (3) Overall clinical analysis so let us examine the same through literature survey.

\section{Diagnosis}

The diagnosis of disease starts from the patient's input in form of signs and symptoms of discomfort of disease at body location/feelings and ends with the complete investigation of disease through laboratory tests. In this process, clinicians firstly, analyze the signs and symptoms in relation to anatomical causatives like distortions in shapes, sizes, locations, orientations, pathways and configurations of anatomical macro/microstructures forming organs and systems of human body by physical examination through inspection, palpation, percussion and auscultation [33], and then investigate the location of causative factors. This completely depends on a precise knowledge of surface Anatomy with respect to relevant anatomical landmarks in relation to concealed internal distorted morphology of structures, organs, limbs and systems.

Then, advanced investigations are done by mapping of signs and symptoms of discomforts, disease and anatomical structural anomalies like distortions or variations in structures causing impairment of activities and/or functions (Fig. 2A, B) along with changes of sensation in structures, organs, limbs, and systems. These diagnostic parameters are having very complexly interwoven, interdependent and interrelationship among them so these can be assessed only with help of necessary and sufficient Anatomy to correctly diagnose the diseases for administering the right treatment.

The anatomical structural distortions are examined by interpretation of radiological images of extra growth in bones, hard masses, stones, injury, extra-development of bodies and variant attachment of tendon/ligaments/fibers in organs/systems and degeneration of macro/microstructures due to interaction of two structures and histological slides including other pathological tests for changes at micro-level. With advances in science and technology, new techniques and equipment have been innovated to facilitate diagnosis and treatment. The use of these tools requires detailed and precise knowledge of Anatomy for its efficient application and analysis. Therefore, physicians are required to have proficiency and skill to compare defective/injured macro/microstructures with normal ones. This is only possible when clinicians have a sound knowledge of most essential Anatomy. It has been found that clinicians either say they require least Anatomy or they diagnose with overconfidence of without knowing necessary and sufficient Anatomy. The clinicians guiding/exercising clinical Anatomy for clinical analysis often have neither the time to update anatomical knowledge nor remember it to the required level as "Perhaps we don't know what we thought we knew: Why clinicians need to revisit and re-engage with clinical anatomy" [8]. Specialty practitioners dealing with more critical patients suffering from more complex and advanced diseases, certainly, require more precise diagnosis to explore macro/microstructural distortion/deformation to be manipulated by medicines. This will involve most essential and more detailed Anatomy far beyond that provided by undergraduate teaching.

\section{Treatment}

As elaborated in the preceding section, the generalized/ weighted mean viewpoints from all populations established that Anatomy is most essential in clinical practice (Tables 3, $4,5)$. This applies at all stages of diagnosis and assessment of the medicinal or surgical treatment. All these stages have an underpinning of anatomical knowledge and understanding. In other words, not only diagnosis but also analysis of treatment depends on anatomical structural deformations as the new drugs/medicinal molecules/antibiotic medicines, for manipulation, restoration, activation, or dissolution are location, structure, organs, system, impairment and disease specific, so these cannot be administered without detailed knowledge of most essential Anatomy for such clinical analysis. For example, (1) the treatment through specific drug or medicines of stones in the gall bladder or kidney or infection in lungs and other organs together with (2) extra growth in bone due to cancer or clinical complications like 


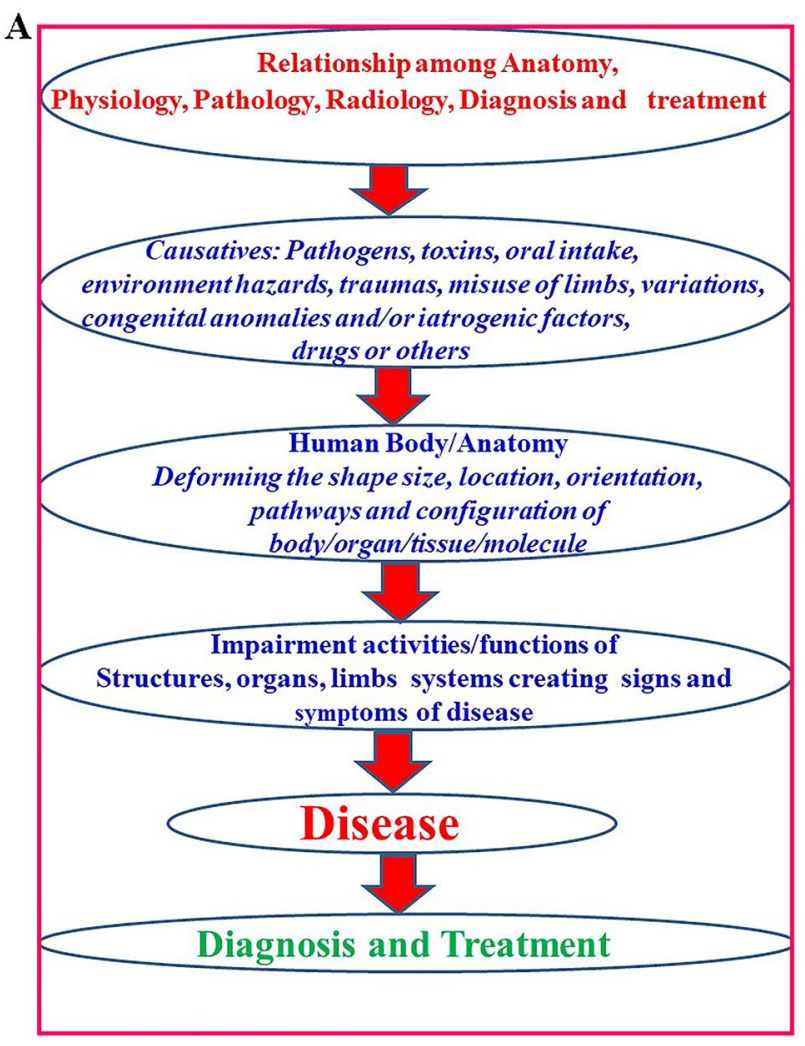

B
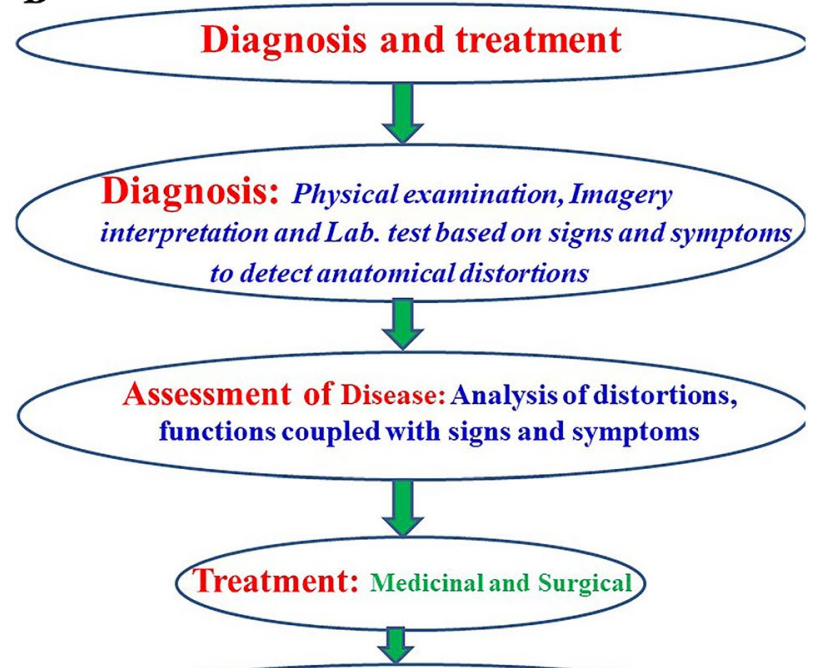

1. Medicinal: For manipulating restoration of anatomical distortions so functions by medicines without side-effect

-
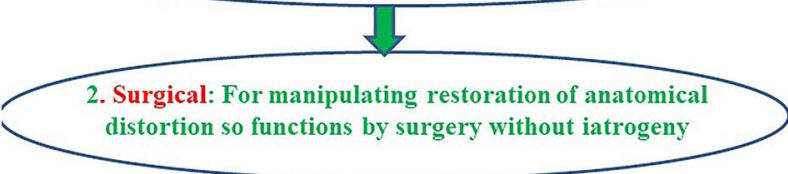

Fig. 2 A Shows interwoven interrelationship of Anatomy with physiology, pathology and radiology. B Shows interwoven interrelationship of Anatomy with Diagnosis and analysis of treatment

ischemia, nerve irritation and/or degeneration of microstructure etc., including (3) if there is swelling in a structure/ organ, are followed by monitoring of images and imagery interpretation dependent on knowledge of Anatomy. Thus, Pathology and Radiology cannot be comprehended without sound knowledge of Anatomy as "a mechanic does not know the parts of the machine, automobile, or television set, he is repairing, it is unlikely that it will work in the end. So, physicians, regardless of their specialty, must know and appreciate gross anatomy" [3].

In illustrations like these, the role of anatomical knowledge can be overlooked since by the treatment stages, it has become thoroughly integrated into the clinicians' vocabulary. However, any inadequacies in that knowledge may appear all too starkly in misdiagnosis and inappropriate treatment. In such circumstances, the possibility of misdiagnosis and mistreatment may be high.

However, the pseudo-concept of requiring inadequate levels of Anatomy may lead to such hazards as instant suppression of signs and symptoms to the detriment of patients' welfare and health. Such treatment not only produces no relief, side-effects/reactions to drugs, may weaken the immune system of the body and may also lead to additional costs in the health care system including the litigation in failure cases. Therefore, in case of litigation in medicolegal complications, the defense of physician and the claim from insurance companies, in relation to the manipulation, restoration, activation, or dissolution of structural deformations in shapes, sizes, locations, orientations, pathways and configurations of known/unknown millions of external/ internal anatomical macro/microstructures forming organs and systems of human body, can be successfully pleaded on the basis of clear and in-depth anatomical knowledge.

\section{Research}

All too often Anatomy is regarded by some as being moribund and stuck in an unchanging past. This is seriously misguided and detrimental to anatomical education, since it pits Anatomy against the excitement of the rapidly moving disciplines, such as virology, genetics and molecular biology. They are rapidly moving but to place all the stress on them as the bases for clinical disciplines is hazardous. No matter how much they contribute to contemporary medicine and to its bioscience foundations, they cannot survive without a wealth of fundamental knowledge across the broad spectrum of the pre-clinical and clinical sciences. Not to speak of this, clinical Anatomy itself is 
moving. A glance at any of the earlier editions of Gray's Anatomy and an edition produced in the twenty-first century is enough to demonstrate that the details of the Anatomy of the first part of the twentieth century and the first part of this century are separated by a gulf of enormous proportions. And this gulf is down to the research undertaken across all branches of Anatomy. While many of these details may not be required by every undergraduate medical student, the concepts that drive the clinical sciences are being transformed by the vibrancy of contemporary Anatomy. This is why it is appropriate to regard anatomical education as being essential for much in medicine.

\section{Conclusion}

These data, bringing out overall generalized mean viewpoints of all the groups and total populations, reveal that the Anatomy is most essential for successful clinical practice consisting of diagnosis and treatment supporting the concept, 'inadequate anatomical knowledge for physicians, is hazardous for successful clinical practice'.

Diseases, distorting anatomical structures/organs/limbs or systems are responsible for impairment of functions and activities. These dysfunctions create signs and symptoms of diseases. The accurate diagnosis and analysis of treatment can be carried out by exploring the interwoven interrelation between diseases, signs and symptoms and distortions or injuries in the anatomical structures/organs/ systems. It clearly establishes that the knowledge of Anatomy is 'most essential'.

The diagnosis and treatment can further be refined by intensive research in grey areas of medical sciences consisting of standalone Human Anatomy and collaborative multidisciplinary research by medically qualified anatomists and others to enhance healthcare.

\section{Limitations}

1. The eruption of COVID-19 pandemic interrupted the collection of data.

2. The varied knowledge and experience in Anatomy and clinical analysis of various populations influenced the feedback.

3. The knowledge of English of populations was variable and so some questions might have been misunderstood.

4. Certain participating populations had no exposure to clinical care.
Author contribution RS: protocol development, data analysis, manuscript writing. NY: data collection. MP: data collection. DGJ: critically reviewing/editing the manuscript.

Funding Nil.

\section{Declarations}

Conflict of interest The authors declare that they have no conflict of interest.

\section{References}

1. Ahmed K, Rowland S, Patel V, Khan RS, Ashrafian H, Davies DC, Darzi A, Athanasiou T, Paraskeva PA (2010) Is the structure of anatomy curriculum adequate for safe medical practice? Surgeon 8(6):318-324. https://doi.org/10.1016/j.surge.2010.06.005 (Epub 2010 Jul 8 PMID: 20950770)

2. Barlow DH (1981) On the relation of clinical research to clinical practice: Current issues, new directions. J Consult Clin Psychol 49(2):147-155. https://doi.org/10.1037/0022-006X.49.2.147

3. Beahrs OH (1991) Gross anatomy in medicine. Clin Anat $4: 310-312$

4. Bergman EM, Van der Vleuten CP, Scherpbier AJ (2011) Why don't they know enough about anatomy? A narrative review. Med Teach 33(5):403-409

5. Bhangu A, Boutefnouchet T, Yong X, Abrahams P, Joplin R (2010) A three-year prospective longitudinal cohort study of medical students' attitudes toward anatomy teaching and their career aspirations. Anat Sci Educ 3:184-190

6. Cahill DR, Leonard RJ, Marks SC Jr (2000) Standards in health care and medical education. Clin Anat 13:15

7. Chia $\mathrm{T}$ (2020) Anatomy teaching by only medically qualified faculty is infeasible. Surg Radiol Anat 42(7):857. https://doi.org/10. 1007/s00276-020-02454-2 (Epub 2020 Mar 12)

8. Cornwall J (2013) Perhaps we don't know what we thought we knew: Why clinicians need to re-visit and re-engage with clinical anatomy. Australas Med J 6(6):339-340. https://doi.org/10. 4066/AMJ.2013.1676 (Published online 2013 Jun 30; PMCID: PMC3702139PMID: 23837082)

9. Cottam WW (1999) Adequacy of medical school Gross anatomy as perceived by certain postgraduate residency programs and anatomy course directors. Clin Anat 12:55-65

10. Craig S, Tait N, Boers D, McAndrew D (2010) Review of anatomy education in Australian and New Zealand medical schools. ANZ J Surg 80:212-216

11. Drake RL, McBride JM, Lachman N, Pawlina W (2009) Medical education in the anatomical sciences: the winds of change continue to blow. Anat Sci Educ 2:253-259. https://doi.org/10.1002/ ase. 117

12. Duparc F, Grignon B, Kachlik D (2019) Editorial: history in anatomy education. Surg Radiol Anat 41(10):1101-1102. https://doi. org/10.1007/s00276-019-02335-3

13. Dusseau J, Knutson D, Way D (2008) Anatomy correlations: introducing clinical skills to improve performance in anatomy. Fam Med 40(9):633-637

14. Ellis H (2002) Medico-legal litigation and its links with surgical Anatomy. Surgery $20: \mathrm{i}-\mathrm{ii}$

15. Evans DJR, Watt JD (2005) Provision of anatomical teaching in a New British Medical School: getting the right mix. Anat Rec (part B: new anat.) 284B:22-27

16. Fitzgerald JE, White MJ, Tang SW, Maxwell-Armstrong CA, James DK (2008) Are we teaching sufficient anatomy at 
medical school? The opinions of newly qualified doctors. Clin Anat 21:718-724

17. Goodwin $\mathrm{H}$ (2000) Litigation and surgical practice in the UK. Br J Surg 87(8):977-979

18. Jones DG (1997) Reassessing the importance of dissection: a critique and elaboration. Clin Anat 10:123-127

19. Leveritt S, McKnight G, Edwards K, Pratten M, Merrick D (2016) What anatomy is clinically useful and when should we be teaching it? Anat Sci Edu 95:468-475

20. Levine MG, Stempak J, Conyers G, Walters J (1999) Implementing and integrating computer-based activities into a problembased gross anatomy curriculum. Clin Anat 12:191-212

21. Lockwood AM, Roberts AM (2007) The anatomy demonstrator of the future: an examination of the role of the medically qualified anatomy demonstrator in the context of tomorrow's doctors and modernizing medical careers. Clin Anat 20:455-459

22. London DA, Andelman SM, Christiano AV, Kim JH, Hausman MR, Kim JM (2019) Is Wikipedia a complete and accurate source for musculoskeletal anatomy? Surg Radiol Anat 41(10):11871192. https://doi.org/10.1007/s00276-019-02280-1 (Epub 2019 Jul 1)

23. Luis-Alfonso AA, Sánchez-Montesinos I, Mirapeix RM, MompeoCorredera B, Sañudo-Tejero JR (2010) Relevance of human anatomy in daily clinical practice. Ann Anat 192(6):341-348

24. Moxham BJ, Plaisant O (2007) Perception of medical students towards the clinical relevance of anatomy. Clin Anat 20(5):560-564

25. Older J (2004) Anatomy: a must for teaching the next generation. Surgeon 2(2):79-90

26. Priyadharshini NA, Dinesh Kumar V, Rajprasath R, Devi R (2019) Relevance of learning anatomy to clinical practice: perceptive of medical students, interns, and clinicians. Natl J Clin Anat 8:3237. https://doi.org/10.1055/s-0039-1688893 (3)
27. Raj K, Singh R (2020) Model pedagogy of Human Anatomy in Medical Education. Surg Radiol Anat 42(3):355-365. https://doi. org/10.1007/s00276-019-02331-7

28. Roche A, Hunter L, Pocock N, Brown D (2009) Physical examination of the foot and ankle by orthopaedic and accident and emergency clinicians. Injury 40:136-138

29. Saket $T$ (2006) The anatomy knowledge of surgical trainees: the trainer's view. Bull R Coll Surg Engl 88:240-242

30. Singh R, Tubbs RS, Gupta K, Man S, Jones DG, Kumar R (2015) Is decline of Anatomy is hazardous to medical education/ profession? A review. Surg Radiol Anat 37(10):1257-1265

31. Smith CF, Mathia HS (2011) What impact does anatomy education have on clinical practice? Clin Anat 24(1):113-119

32. Smith JA (2005) Can anatomy teaching make a comeback? ANZ J Surg 75:93

33. Standring S (2012) Evidence-based surface anatomy. Clin Anat $25: 813-815$

34. Turney BW (2007) Anatomy in a modern medical curriculum. Ann R Coll Surg Engl 89(2):104-107. https://doi.org/10.1308/ 003588407X168244 (PMCID:PMC196455 PMID:17346399)

35. Turney BW, Gill J, Morris JF (2001) Surgical trainees as anatomy demonstrators: revisited. Ann R Coll Surg Engl (Suppl) 83:193-195

36. Waterston SW, Stewart IJ (2005) Survey of clinicians' attitudes to the anatomical teaching and knowledge of medical students. Clin Anat 18(5):380-384

Publisher's Note Springer Nature remains neutral with regard to jurisdictional claims in published maps and institutional affiliations. 